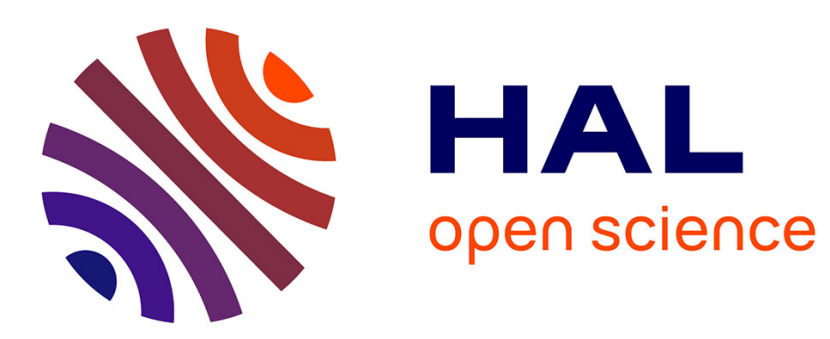

\title{
Social Networks and Normative Context
}

Alexis Ferrand, Jacques Marquet, Luc van Campenhoudt

\section{To cite this version:}

Alexis Ferrand, Jacques Marquet, Luc van Campenhoudt. Social Networks and Normative Context. Bajos N., Hubert M., Sandfort T. Sexual Behaviour and HIV/AIDS in Europe., UCL Press, London, pp.303-327, 1998. halshs-00266638

\section{HAL Id: halshs-00266638 \\ https://shs.hal.science/halshs-00266638}

Submitted on 26 Mar 2008

HAL is a multi-disciplinary open access archive for the deposit and dissemination of scientific research documents, whether they are published or not. The documents may come from teaching and research institutions in France or abroad, or from public or private research centers.
L'archive ouverte pluridisciplinaire HAL, est destinée au dépôt et à la diffusion de documents scientifiques de niveau recherche, publiés ou non, émanant des établissements d'enseignement et de recherche français ou étrangers, des laboratoires publics ou privés. 


\section{Social Networks, Normative Context}

\section{By Alexis Ferrand ${ }^{1}$, Jacques Marquet and Luc Van Campenhoudt²}

Chapter 11 in Bajos N., Hubert M., Sandfort T. (eds).

\section{Sexual behaviour and HIV/AIDS in Europe.}

London, UCL Press, 1998, p. 303-327

\section{Introduction}

This chapter illustrates some issues which can be defined as coming under 'the social networks' approach, which is composed of both a general paradigm (Degenne, 1983; Degenne and Forse, 1994; Ferrand and Snijders, 3997; Wellman and Berkowitz, 1988) and various kinds of methodologies (Wasserman and Faust, 1994; Marsden, 1990). In this approach, individuals are seen as actors who behave intentionally and try to manage the gap between desires and prohibitions, goals and resources. Their relations, and the networks they form, are effects and conditions of actions - effects when actors bargain to create or transform relations, conditions when relations provide resources and alternatives, or impose constraints on actions. Then existing relations influence some emerging or other existing relations. Another way of saying this is that some kinds of relations - not all - are interdependent or form 'systems'.

Sometimes researchers can describe a whole network, that is, all relations of a given kind amongst a given set of people: pupils in a classroom, subset of a local elite, and so on. But such a methodology is often limited to the deep structural description of limited milieus. Sexual research on large populations uses questionnaires administered to randomly selected, a priori unconnected people. The methodology forbids direct description of the whole network,

\footnotetext{
1 Professor, University Lille 1, member of the CNRS CLERSE

2 Both professors in sociology, Catholic University of Louvain and St Louis University Bruxelles in Bajos N., Hubert M., Sandfort T. (eds). Sexual behaviour and HIV/AIDS in Europe. London, UCL Press,
} 
but allows the statistical description of 'personal networks' in given populations. In mass surveys it "is possible to ask interviewees to describe some personal relationships as elements of their environments. Data provided by such surveys can then be used to define simulation models' parameters of comprehensive sexual networks (Kretzschmar et al., 1994).

Sex surveys ask individuals to describe some - two, three, more recent sexual relationships. It is possible to conceptualize sexual links as interdependent if they are reciprocally conditioned, for example, when an existing primary relation influences the content of a secondary one, and when the latter allows - or in other cases endangers - the continuation of the former. The diverse rewards and costs of each link can be balanced. More generally, for different kinds of links, the resources provided and constraints imposed by relations are extremely varied, giving rise to myriad forms of interdependencies.

This chapter focuses on a small range of such interdependencies because the few available surveys that provide information on the relational environment of actors describe specific links and limited features of personal networks. Our aim is not to demonstrate that the number, content, and forms of sexual relations depend upon such or such interpersonal relations. This would call for complex multivariate statistical analysis. Through simple cross tabulations we want to illustrate and to give some credibility to specific hypotheses by showing that basic trends in relational processes, structures, and interdependencies exist.

For the first issue, we assume that a change in sexual behaviour implies change in the definition of situations that is facilitated and supported by discussions about emotional and sex affairs. That depends upon the composition of the personal network: mainly, do actors speak of emotional and sexual affairs with someone in their environment? Here we take the direct functional effect of symbolic exchanges and supports as a given, but we examine major trends which define who can and cannot talk, and which indirectly affect the ability to transform sexual relations.

The second and third issues refer to the effect of the perception of personal networks' boundaries, that is, the effect of perceived relational proximity to 'the risk'. Most people perceive themselves as 'straight' and 'clean', since they conceive of their personal networks as 'straight' and 'clean', given the dominant representation which suggests that HIV risks are 'out there', in foreign, distant milieus. So, the chance of knowing a seropositive individual is first conceived of from a positivist point of view as a quasi mechanical effect of networks' sizes and compositions in communities with various HIV prevalences. We suppose that knowing a person with HIV / AIDS (PWHA) is important enough to increase information about, and fear in Bajos N., Hubert M., Sandfort T. (eds). Sexual behaviour and HIV/AIDS in Europe. London, UCL Press, 
of, the illness to the point where Ego may reconsider the network boundary between him/ herself and PWHAs. Our second hypothesis, therefore, is that the personal network definition influences Ego's sexual behaviour (use of condoms, or other changes) when he perceives HIV as a risk in his/her world.

The third issue focuses more specifically on perceptions of possible chains of sexual relations. By definition, an exclusive sexual relation is the simplest, most bounded, sexual network. The question of reciprocal risk of HIV transmission can be managed by the dyad, mainly at the beginning of the relation. On the contrary, if one supposes that a simultaneous partner's partner exists, Ego can perceive the relation as a simple element in a more or less unbounded, potentially risky network.

The fourth issue relates to the social network's normative influence. Our hypothesis is that norms of close relationships influence Ego's norms and behaviour. The first question is to examine if these norms are homogeneous or not, and if there are one or several potential influences. The second is to describe the correspondence between the norms people perceive in their networks and their own norms and behaviour.

We shall present for each of these topics the principal social issues involved, the way each survey formulated questions and operationalized variables, the most interesting comparative analyses, and comments about these comparisons, especially convergent and divergent trends. Unlike the approach developed in most of the other chapters, that is, one focusing on comparisons between countries, here we shall focus on the potential relevance of a number of research questions which will be explored using information from separate countries. Data from only three countries - Belgium (1993), France (ACSF 1992) and the Netherlands (1989) - are included.

The populations taken into account are all respondents between the ages of 18 and 49 in some cases, and all individuals between the ages of 18 and 49 who have already had sex over a specified period (in the course of the lifetime, over the past five years, or over the past 12 months) in other cases. In the questionnaires we are considering, some of the questions were asked of a random subsample only. As a result, the total reference population may vary from one question to the next and thus from one table to the next.

Several variables were chosen for cross-tabulation with dependent variables. We have selected those which are the more common in comparative studies but also the more pertinent regarding personal networks' properties: age, gender, and size of the community of residence, 
which are known to influence the composition of people's networks; and the number of sexual partners as a very rough indicator of sexual socialization.

\subsubsection{The Network of Confidents}

We assume that the possibility of talking about one's emotional and sex life with one or more confidants has an effect on the ability to control sexual behaviour (at both the cognitive and affective levels) and possibly to respond to HIV risk, even if these discussions do not explicitly concern HIV risk (Ferrand and Mounier, 1993b). First, these discussions produce new frames for apprehending daily life and organizing one's experiences, and, we suppose, in particular, for understanding HIV transmission risks and changing views about potential means of protection. Second, the disclosure of private life allows close relationships both to control and to support actors' sexual behaviours or opinions. In contrast, an inability to find confidants or a deliberate choice to avoid confiding one's secrets can make the selfassessment of behaviour more difficult and leave the individual without reference points.

If we accept these presuppositions, it is important to know which categories of people can talk in confidence about such subjects with a close friend or relative. We shall thus start by trying both to establish the profile of the kind of person who can count on confidants and to understand confidants' places within his or her social network. To do this, we shall focus on the link between the number of confidants and the size of the network of friends and relatives.

The question of confidants was tackled in a similar manner in only two surveys, the Belgian and French ones. The relevant questions, which did not refer explicitly to discussions about HIV risk, were "There are some people with whom you can discuss personal matters. With how many people besides the person with whom you are living do you discuss love affairs, sexual problems or venereal disease or marital relations?" in the French survey and "If you felt the need to talk about your emotional and sex life, could you count on someone other than your main partner in whom you could confide, a sort of confidant?” in the Belgian survey. The Belgian and French surveys' wordings of the question are analogous, even though some minor differences might partly explain differences in the response rates for the two countries, and differences in the degrees of association with other variables. While the word 'confidant' is stated explicitly in the Belgian question, this is not the case in the French question. The latter also draws a slightly different picture of 'confidant' involving a less intimate connotation 
through the use of the verb 'to discuss with' rather than 'to confide in'. The two surveys also make reference to different time frames. The French question considers current confidants, while the Belgian question enables one to group current and supposed potential confidants through the use of the conditional. Finally, the Belgian and French questions exclude different groups of people from their lists of confidants, namely, the partner of a one-partner interviewee and the main partner of a multiple-partner interviewee in the case of the Belgian survey, and the respondent's cohabitant in the case of the French survey. As a result, the confidant of the Belgian survey is not quite the confidant of the French survey. Still, we can nevertheless posit that the two notions overlap considerably.

Having set the stage, let us now look at the findings. Twenty-four and a half per cent of the French respondents declared they had a confidant and 45.0 per cent stated they had more than one confidant, compared with 45.8 and 30.6 percent, respectively, of the Belgian respondents. The key finding is that roughly a quarter of the respondents in each country said they had no one with whom they could talk over emotional and sexual matters. The characteristics of this subpopulation can be deduced from Table 11.1 
Table 11.1 Proportions of individuals who have at least one confidant to talk over emotional and sexual matters

\begin{tabular}{|c|c|c|c|c|}
\hline & \multicolumn{2}{|c|}{ Belgium 1993} & \multicolumn{2}{|c|}{ France 1992} \\
\hline & $\%$ & $\mathrm{~N}$ & $\%$ & $\mathrm{~N}$ \\
\hline All & 76.4 & 1392 & 69.5 & 2049 \\
\hline \multicolumn{5}{|l|}{ Sex } \\
\hline Men & 70.0 & 653 & 61.4 & 1132 \\
\hline Women & 82.1 & 739 & 77.9 & 917 \\
\hline \multicolumn{5}{|l|}{ Age } \\
\hline $18-19$ & 90.6 & 101 & 92.5 & 146 \\
\hline $20-24$ & 87.5 & 229 & 79.9 & 508 \\
\hline $25-29$ & 82.6 & 220 & 75.9 & 435 \\
\hline $30-39$ & 73.2 & 449 & 68.6 & 589 \\
\hline $40-49$ & 67.7 & 393 & 54.9 & 371 \\
\hline \multicolumn{5}{|c|}{ Number of partners over last year } \\
\hline Never had sex & 89.4 & 88 & 82.0 & 65 \\
\hline 0 & 69.0 & 50 & 78.6 & 120 \\
\hline 1 & 74.5 & 1087 & 66.8 & 1153 \\
\hline$>1$ & 85.5 & 167 & 81.4 & 711 \\
\hline
\end{tabular}

In both the French and Belgian surveys, a higher percentage of women than men said they had one or more confidants. The number of people who said they had at least one confidant diminished with age. These percentages declined steadily from similar initial values. However, the decline was more marked in the French survey.

Likewise in both surveys more people with multiple partners than with single partners had at least one confidant. Talking about and having sexual relations thus seem to be two forms of interpersonal exchange that go hand in hand. Nevertheless, 14.5 per cent (in Belgium) and 18.6 per cent (in France) of the respondents who engaged in sex with more than one person in the course of the previous 12 months had no one with whom they could talk about sexual matters and possible HIV risk-related behaviour.

Inversely, we must also point out that many of the respondents who stated they had no sexual partner both over the previous 12 months and in general nevertheless had at least one confidant to talk to about emotional and sexual matters. The existence of at least one person with whom one can talk should doubtless be considered as the effect of both sociability and the particular need to exchange information and opinions about these matters. Similarly, 
despite an absence of sexual activity, many young people stated they had at least one confidant to talk to about emotions and sex.

The confidants generally form a sub network within a set of 'significant others', that is, people perceived as 'close' and important even if they do not meet very often. The more extensive the network of significant others, the greater the theoretical chances of having confidants. This link between the size of the network of significant others and number of confidants can be examined for the Belgian survey only, in which a variable embracing the size of the network of significant others (NSO = number of significant others) was constructed from the questions concerning the family, professional, and social (leisure-time ) networks ${ }^{3}$. As hypothesized, the results show that the more extensive a network is, the greater the chances of finding at least one person with whom one can talk about one's emotional and sex life ${ }^{4}$. Still, some people do not have any confidants despite an extensive network, many close friends and relatives. Very contrasting reasons can explain such situations, for example, not needing to talk about one's private life, social taboos about sexual disclosure, or psychological inhibition. This link between the size of the network of close friends and relatives and the number of confidants is influenced by the respondent's gender. As we have seen, women, as a rule, have more confidants than men. This is borne out in both the French and Belgian surveys. In contrast, the Belgian data show that men generally had more extensive social networks than women ${ }^{5}$. However, this difference may have resulted to a certain extent from the way the index was designed, as more women than men have no job and thus no colleagues with whom to achieve the maximum score of nine significant others.

These two surveys show that people without confidants tend to be men rather than women, older rather than young, have one partner rather than multiple partners, and have rather smaller social networks. Locality size does not seem to influence this characteristic. However, as bivariate rather than multivariate analyses were performed, we cannot assert that it is

\footnotetext{
3 The question was worded as follows: 'Do you have people you feel close to, that is to say, friends or at least very good chums, in the circles that I am going to read out? How many people / in your family (extended family) / at work or your place of study / whom you meet through leisure activities / would you say you are close to?' The score for each of these circles could be $0,1,2$, or 3 (for three or more persons to whom the respondent felt close). Adding the scores for the three questions could give a maximum cumulative score of nine for respondents with at least three close friends/relatives in each circle. This index does not correspond strictly to the network's size, however. Rather, it expresses the network's structure. Thus, a person who had 10 confidants among his/her friends and family but not a single confidant among his/her workmates would have a score of only six.

4 Sixty-one per cent of the people who had NSO scores of from zero to three had at least one confidant, compared with 82.1 per cent of the respondents who scored nine.

5 Of the male respondents 45.6 per cent had a NSO score of nine (nine or more significant others) versus 37.5 per cent of the female respondents.
}

in Bajos N., Hubert M., Sandfort T. (eds). Sexual behaviour and HIV/AIDS in Europe. London, UCL Press, 
necessarily the same people who combine all these different characteristics, nor can we give a general profile of the confidant-less individual.

Even if we have identified only a few of the properties that characterize confidants' networks, without showing how networks influence representations, opinions, and behaviour, these results tell us something very important about the exposure of individuals to social pressure. If prevention messages are to be understood and applied, we have to seek explanations in individuals' characteristics as well as in the social network processes by which an important part of the information received is transformed into interpersonal knowledge and control.

\subsubsection{Knowing Someone with HIV / AIDS and Sexual Behaviour}

Many studies (for example, Pollak, 1988) have stressed the importance of knowing one or more PWHA on a person's perception of the risk of HIV infection. Some authors (for example, Catania, Kegeles' and Coates, 1990) have even considered this factor to be decisive in triggering behaviour change.

Table 11.2 Proportions of people stating they know at least one PWHA

\begin{tabular}{|c|c|c|c|c|c|c|}
\hline & \multicolumn{2}{|c|}{ Belgium 1993} & \multicolumn{2}{|c|}{ France 1992} & \multicolumn{2}{|c|}{ Netherlands 1989} \\
\hline & $\%$ & $\mathrm{~N}$ & $\%$ & $\mathrm{~N}$ & $\%$ & $\mathrm{~N}$ \\
\hline All & 8.1 & 2810 & 14.8 & 2049 & 7.7 & 990 \\
\hline \multicolumn{7}{|c|}{ Place of residence } \\
\hline Rural & 5.8 & 85 & 11.3 & 421 & 2.5 & 40 \\
\hline Small towns & 6.4 & 1405 & 14.4 & 438 & 5.9 & 699 \\
\hline Towns & 9.0 & 410 & 15.5 & 755 & 13.5 & 251 \\
\hline Brussels/Paris & 16.5 & 910 & 19.7 & 424 & & \\
\hline \multicolumn{7}{|c|}{ No. of partners over last year } \\
\hline Never had sex & 2.6 & 172 & 11.8 & 71 & 4.3 & 47 \\
\hline 0 & 7.5 & 94 & 12.0 & 120 & 7.1 & 70 \\
\hline 1 & 7.9 & 2198 & 13.4 & 1149 & 7.7 & 759 \\
\hline$>1$ & 13.2 & 346 & 27.0 & 709 & 13.1 & 114 \\
\hline
\end{tabular}

In this section we first approach this question by focusing on the conditions that lead someone to know a PWHA. We begin by a comparative description of the situation (Table 11.2). From a positivist point of view, various probabilities of knowing a PWHA can be analyzed as 
mechanical effects of the prevalence of cases and the differential social 'reachability' of the cases. This last point is dependent on networks' sizes, boundaries, structures, and overlapping in a large population. Even if we do not have indicators for these broad properties for large interpersonal or sexual networks, we can use the available personal network variables as local indicators of some characteristics of large networks to examine their effects. A second approach goes back to the hypothesis that knowing a PWHA reinforces safe sexual behaviour and examines simple comparative cross-tabulations on the potential influence of knowing one or more PWHA on condom use. These research questions were not handled identically by the Belgian, French, and Dutch surveys. However, bipartite and often tripartite comparisons are possible.

The surveys used slightly different wordings in tackling the issue of acquaintance with PWHA ${ }^{6}$. The Belgian survey took people with HIV, people with AIDS, and the deceased victims of AIDS into account; the French survey did not take the deceased into account; and the Dutch survey did not explicitly include people with HIV in the formulation. The percentage of respondents who stated they knew at least one PWHA in France (14.8 per cent) was higher than those recorded in the Netherlands (7.7 per cent) and in Belgium (8.1 per cent).

These differences doubtless are due in part to the three countries' respective HIV prevalences. The cumulative AIDS case rates at the times the surveys were conducted were 0.341 per thousand for France, 0.078 per thousand for the Netherlands, and 0.137 per thousand for Belgium $^{7}$. The HIV prevalence rate was three to four times higher in France, where the proportion of people who knew a PWHA was about twice as high as in the other surveys. But, as suggested above, rates are only one of two combined conditions. Fairly similar prevalence rates can be associated with a) different virus dissemination patterns due to the relative closeness of the riskiest sexual milieus, and/or b) various social 'reachabilities' of PWHA due to the relative closeness of social milieus. A typical case here is Belgium where it is known that, unlike other countries, non-residents account for a large proportion of notified cases. If

\footnotetext{
6 The questions are 'Do you persona]]y know one or more people in your entourage, that is, family, friends, officemates, and neighbours, who are seropositive, in with AIDS, or have died from AIDS?' for the Belgian survey; 'Do you personally know one or more individuals (family, friends, co-workers) who are seropositive or have AIDS?' for the French survey; and 'Have you ever personally known someone who has or had AIDS?' for the Dutch survey.

${ }^{7}$ European Centre for the Epidemiological Monitoring of AIDS (1995), AIDS Surveillance in Europe, Quarterly Report, 47, Saint-Maurice.
}

in Bajos N., Hubert M., Sandfort T. (eds). Sexual behaviour and HIV/AIDS in Europe. London, UCL Press, 
we assume that such individuals have fewer social contacts with the resident population, this can account for a lower rate of people knowing a PWHA at a given HIV prevalence rate.

A more precise analysis of these effects can take into account the size of the community of residence and the number of sexual partners over the previous 12 months. A clear link between the probability of knowing a PWHA and the size of the locality appears. Although the numbers of Belgian and Dutch respondents residing in rural localities of less than 5000 inhabitants are too small to draw statistically reliable conclusions concerning this relationship, the overall trend is clear and analogous in all three countries, namely, the probability of knowing one or more PWHA increases with the size of the locality of residence (between the villages and capital it doubles in France and triples in Belgium). That can be interpreted as an effect of the higher prevalence of HIV in large cities, but also as an effect of different social norms: the moral contexts specific to small towns and villages may prevent people disc1osing their seropositivity.

Having multiple sexual partners has virtually the same influence in all three countries. The proportion of people who reported knowing at least one PWHA practically doubles between the group of respondents who had no or one sexual partner over the previous 12 months and those who had two or more partners (the 'multiple-partner' group). In this simple crosstabulation the number of sexual partners is a direct indicator of the size of the sexual network, which thereby increases the chances of meeting a PWHA and of belonging to networks where the proportions of PWHA are greater (because they are more numerous and disclosure of serological status is better tolerated), but it can also be interpreted as an indirect indicator of general types of sociability.

Indeed we can wonder if the first and more general condition for knowing a PWHA is not simply knowing a lot of people, regardless of who they are: That assumption can rest on the relative ambiguity of the term 'to know' combined with the effect of 'weak ties'. Through weak ties - typical of large networks people are connected with people out of their social (and sexual) world. We tested the hypothesis that the more contacts an individual has, the greater the probability of his/her being informed that someone among them is seropositive. The data from the Belgian survey, which is the only one for which the influence of the size of the 'significant others' network could be verified, show that the proportion of respondents who know or have known at least one PWHA does not vary significantly with the size of the network of 'significant others'. 
The real issue is the number of channels through which information about someone's serostatus can flow, and only particular relationships, such as those with confidants, can permit such disclosure. We therefore examined the influence of the number of confidants (people with whom one talks about one's emotional and sex life) in the French and Belgian surveys. In both surveys, respondents who had two or more confidants were more likely to know at least one PWHA than those who had only one confidant. The probabilities of knowing a PWHA depend on the number of confidants. Those who have no confidant, know a PWHA less often than those who have one confidant in France, but more often in Belgium. The greater the number of channels through which it is possible to speak about sexual affairs, the greater the chance of knowing a PWHA. However, this factor is far from being the only one involved, as the disparities among the Belgian data show.

Let us examine comparative cross-tabulations with the potential influence of knowing one or more PWHA. Two kinds of influence can be analyzed in the surveys: a specific influence on condom use, and a more overall influence on sexual behaviour change. In interpreting the results one must bear in mind that many people (people who are not injecting drug users, do not have sex, or who have a steady, one-on-one relationship in which both partners are faithful to each other, and so on) have no objective reason to use condoms or to change their practices because of the HIV epidemic. If it were possible, the number of people who reported condom use or a behaviour change should thus be compared with the percentage of the population who formerly engaged in risky practices.

Table 11.3 summarizes condom use for the previous 12 months according to gender, number of stated sexual partners for the previous 12 months, and knowing or not knowing a PWHA. It shows that respondents who knew at least one PWHA used condoms slightly more often than those who had no HIV infected acquaintances (some deviations are statistically insignificant). And it holds true for each gender, where stated condom use was highest for respondents who knew at least one PWHA. Knowing a PWHA did not have a statistically significant influence on condom use in the 'one-partner' group, but it increased condom use slightly in the 'multiple-partner' group.

We can also analyze the data in relation to our second point: whether knowing a PWHA leads one to change one's own behaviour. Only the French and Dutch surveys provide some elements of the answer to this question ${ }^{8}$. Table 11.4 summarizes the responses to these

\footnotetext{
8 The questions eliciting this information were worded as follows: 'Have you changed your sexual behaviour since people have started talking about AIDS?' in the French survey; and 'Did you do anything to prevent in Bajos N., Hubert M., Sandfort T. (eds). Sexual behaviour and HIV/AIDS in Europe. London, UCL Press,
} 
questions according to gender, stated number of sexual partners over the previous 12 months, and knowing or not knowing a PWHA.

Table 11.3 Condom use by gender, number of sexual partners, and knowing a PWHA

\begin{tabular}{|c|c|c|c|c|c|c|}
\hline & \multicolumn{2}{|c|}{ Belgium 1993} & \multicolumn{2}{|c|}{ France 1992} & \multicolumn{2}{|c|}{ Netherlands 1989} \\
\hline & $\%$ & $\mathrm{~N}$ & $\%$ & $\mathrm{~N}$ & $\%$ & $\mathrm{~N}$ \\
\hline All & 23.9 & 2810 & 29.4 & 2049 & 23.7 & 990 \\
\hline Know PWHA & 31.3 & 309 & 35.7 & 422 & 27.6 & 76 \\
\hline \multicolumn{7}{|l|}{ Gender } \\
\hline Men & 30.4 & 1329 & 33.3 & 1132 & 28.5 & 418 \\
\hline Men, know PWHA & 39.9 & 142 & 39.2 & 227 & 32.4 & 37 \\
\hline Women & 18.0 & 1481 & 25.3 & 917 & 20.3 & 572 \\
\hline $\begin{array}{l}\text { Women, know } \\
\text { PWHA }\end{array}$ & 24.0 & 167 & 32.4 & 195 & 23.1 & 39 \\
\hline \multicolumn{7}{|c|}{ No. of partners over last year } \\
\hline 1 & 21.2 & 2198 & 27.7 & 1153 & 26.6 & 759 \\
\hline 1, know PWHA & 24.6 & 230 & 28.8 & 200 & 18.5 & 54 \\
\hline $2+$ & 62.0 & 346 & 62.8 & 711 & 55.3 & 114 \\
\hline $2+$, know PWHA & 66.7 & 66 & 72.8 & 190 & 80.0 & 15 \\
\hline
\end{tabular}

Table 11.4 Proportions of respondents stating a behaviour change in response to HIV/AIDS

\begin{tabular}{|c|c|c|c|c|}
\hline & \multicolumn{2}{|c|}{ France 1992} & \multicolumn{2}{|c|}{ Netherlands 1989} \\
\hline & $\%$ & $\mathrm{~N}$ & $\%$ & $\mathrm{~N}$ \\
\hline All & 18.5 & 2049 & 11.0 & 990 \\
\hline Know PWHA & 31.9 & 422 & 19.7 & 76 \\
\hline \multicolumn{5}{|l|}{ Gender } \\
\hline Men & 22.7 & 1132 & 17.2 & 418 \\
\hline Men, know PWHA & 38.2 & 227 & 32.4 & 37 \\
\hline Women & 15.0 & 917 & 6.5 & 572 \\
\hline $\begin{array}{l}\text { Women, know } \\
\text { PWHA }\end{array}$ & 26.0 & 195 & 7.7 & 39 \\
\hline \multicolumn{5}{|c|}{ No. of partners over last year } \\
\hline 1 & 15.3 & 1153 & 8.7 & 759 \\
\hline 1, know PWHA & 28.4 & 200 & 18.5 & 54 \\
\hline $2+$ & 43.1 & 711 & 25.4 & 114 \\
\hline $2+$, know PWHA & 46.8 & 190 & 40.0 & 15 \\
\hline
\end{tabular}

infection or do you just consider it impossible for you to have become infected? _ did something to prevent infection - ran no risk at aI!' in the Dutch survey.

in Bajos N., Hubert M., Sandfort T. (eds). Sexual behaviour and HIV/AIDS in Europe. London, UCL Press, 
The first row in Table 11.4 shows that the proportion of respondents in each survey who stated they had changed their behaviour was small, but we can assume ${ }^{9}$ that the proportion of people who have had to change was also relatively small. It shows also that these proportions are different in the two countries: roughly one out of ten respondents in the Dutch survey and one out of five in the French survey declared a behaviour change in response to HIV / AIDS. These differences are probably not unrelated to the year in which each survey was carried out (see Chapter 8). There was much more talk about AIDS in 1992, when the French survey was conducted, than in 1989; the year the Dutch survey was conducted. In an area such as AIDS, where the givens (course of the epidemic, advancement of research, public information, and so on) change quickly (Cohen and Hubert, 1997), the times at which the various surveys were conducted must be taken into account when interpreting differences in their findings.

Now, regarding our hypothesis, Table 11.4 shows the expected result: a higher proportion of the respondents who knew a PWHA changed their behaviour (and this effect was of the same order of magnitude for the two surveys). We have to analyze that general finding to take into account various kinds of sexual conduct linked to various levels of potential risk. If we use the number of partners for the last 12 months, we can see that, generally speaking, fewer onepartner than multiple-partner respondents changed their behaviour (this held true in both studies). The effect of knowing a PWHA is different for each population: it seems to increase the percentage of one partner respondents who change but to have only a slight influence on the proportion of multipartner respondents who change their behaviour (some deviations are statistically insignificant).

These results confirm that knowing a PWHA or counting a PWHA in one's network of personal relations usually prompts people to take the risk of HIV transmission into account, either by using condoms or by making some other behaviour change. Usually this occurs, but not always. The difficulty lies in understanding why and why not. A number of good ad hoc reasons can be proposed. Let us try one to explain the stronger effect amongst the one partner respondents. Most of them are long-term 'monopartners' living in a couple relationship and convinced of their partner's faithfulness (see the section on tolerating love affairs outside stable relationships below) and of the safety of their social and sexual milieu. For that large majority of monopartners, changing their behaviour in response to AIDS would not make any sense to them. But two subpopulations do exist. One is made of sequential monopartners: for

\footnotetext{
9 It cannot be demonstrated due to a lack of information about sexual behaviour before 1985 when sexual VIH transmission began to be a public issue.
}

in Bajos N., Hubert M., Sandfort T. (eds). Sexual behaviour and HIV/AIDS in Europe. London, UCL Press, 
them, knowing a PWHA can be important to increasing information on, and perhaps fear of, the illness. But, more importantly, it can also change their perception of the network boundary between themselves and persons with AIDS, their perception of the presence of HIV risk in their OWN social and sexual network; and that can produce a profound effect. The second group is composed of the people who react to knowing a PWHA by becoming faithful to one partner. For respondents with two or more sexual partners, the weak influence of knowing a PWHA might mean that knowing an infected person is a socially more frequent and less incredible event. That possibility is a characteristic of the kinds of milieu they belong to or occasionally frequent. One does not need a specific personal tie to be aware of HIV risks in one's surroundings. That interpretation stresses the specific effect of knowing a PWHA on the representation of the overall safety of one's social and sexual world. One person can be a symbol of the state of the whole personal network of an individual because the network is known as a more or less generalized exchange network.

\subsubsection{The Steady Partner'sPartners}

From the standpoint of prevention, a key problem is a person's knowledge of his/her partners' sexual network. Although this question is important for everyone, it has special connotations for people with steady partners, for it brings up the issue of multiple partnership within a steady couple that is supposed to operate according to the model of faithfulness. In studying this particular question we shall look at only those individuals who had at least one steady partner for at least five years so as to omit specifically adolescent high partner turnover.

This question is tackled by all three surveys using almost identical terms. There is one notable difference in that the Belgian question, unlike the other two, considers partners' affairs over an indeterminate period of time, not necessarily the entire length of the relationship. Table 11.5 shows the percentages of respondents, by gender, age, and number of partners over the previous year, who said they knew their steady partners had or had had other partners ${ }^{10}$.

\footnotetext{
10 The wordings are as follows: 'To your knowledge, has this person had or did this person have sexual relations with other persons during his/her sexual relationship with you?' (The partner with whom the relationship has lasted more than five years and the respondent last had sex) in the French survey; 'Do you currently believe that this person has sex with someone other than yourself?' in the Belgian survey; and 'Has your partner, during this relationship, ever had sexual contact with someone else?' in the Dutch survey.
}

in Bajos N., Hubert M., Sandfort T. (eds). Sexual behaviour and HIV/AIDS in Europe. London, UCL Press, 
Table 11.5 Respondents’ assessments of their partners’infidelity

\begin{tabular}{|c|c|c|c|c|c|c|c|c|c|}
\hline & \multicolumn{3}{|c|}{ Belgium 1993} & \multicolumn{3}{|c|}{ France 1992} & \multicolumn{3}{|c|}{ Netherland 1989} \\
\hline & $\%$ & $\%$ & $\mathrm{~N}$ & $\%$ & $\%$ & $\mathrm{~N}$ & $\%$ & $\%$ & $\mathrm{~N}$ \\
\hline & Yes & Don't'know & & Yes & Don't'know & & Yes & Don’t'know & \\
\hline All & 4.2 & 5.9 & 1725 & 2.9 & 3.7 & 762 & 6.2 & 2.4 & 532 \\
\hline \multicolumn{10}{|l|}{ Gender } \\
\hline Men & 3.6 & 6.0 & 770 & 1.9 & 1.5 & 426 & 4.2 & 2.6 & 190 \\
\hline Women & 4.6 & 5.9 & 955 & 3.9 & 6.0 & 336 & 7.3 & 2.3 & 342 \\
\hline \multicolumn{10}{|l|}{ Age } \\
\hline $20-24$ & 0.6 & 3.0 & 52 & 3.8 & 6.3 & 39 & 17.4 & 0.0 & 23 \\
\hline $25-29$ & 3.0 & 3.5 & 229 & 2.0 & 2.6 & 141 & 6.8 & 1.4 & 73 \\
\hline $30-39$ & 4.1 & 6.2 & 715 & 2.0 & 4.5 & 333 & 5.0 & 2.9 & 242 \\
\hline $40-49$ & 4.9 & 6.6 & 729 & 3.9 & 3.2 & 249 & 6.2 & 2.6 & 194 \\
\hline \multicolumn{10}{|c|}{ Number of partners over last year } \\
\hline 1 & 3.3 & 5.4 & 1599 & 2.2 & 3.2 & 579 & 5.1 & 2.1 & 513 \\
\hline$>1$ & 17.8 & 15.1 & 126 & 13.4 & 12.9 & 183 & 36.8 & 10.5 & 19 \\
\hline
\end{tabular}

in Bajos N., Hubert M., Sandfort T. (eds). Sexual behaviour and HIV/AIDS in Europe. London, UCL Press, 
The total percentages given in the first row of Table 11.5 show that, overall, a very small percentage of respondents said they knew that their partners had had, or were having, sex with someone else concurrently with their own relationship ${ }^{11}$. At least 90 per cent of the respondents believed they were their steady partners' only partners and thus could 'trust them'. The relatively small number of 'don't knows' indicates that almost all of the respondents truly thought they knew how their partners behaved in this matter.

The age - and gender- dependent effects are quite different, though, in the three surveys. The strongest rise in the belief in one's partner's extra-couple sex was correlated with the increase in the number of the respondent's partners. This may be explained by several partly complementary hypotheses, to wit: a certain number of multipartner respondents most likely live in circles where such behaviour is common; the love affairs or concomitant relationships of one member of a couple may prompt his/her steady partner (often a spouse) to follow suit; some couples have a looser, more flexible relationship than the norm; a certain number of 'steady partners' are actually singles who nevertheless maintain a special relationship; and some multiple-partner respondents may project their 'philandering' onto their partners. The large percentages of 'don't know' may indicate not only doubt but also, in some cases, the respondent's weak commitment to the relationship. Still, these findings and hypotheses should not mask the fact that a large majority of the respondents with multiple partners thought they knew, with certainty, that their steady partners did not have other partners.

We compared the multipartner respondents' answers with regard to the last partner with whom the respondent had sex (usually the main partner with whom the respondent was living, that is $\mathrm{P} 1)$ and the penultimate sex partner (P2), for the French study only. While 13.4 per cent of the French multipartner respondents believed that their P1 had at least one other sexual partner, versus 12.9 per cent 'don't know', the figure rose to 60.6 per cent of the same population for their P2 (versus 15.2 per cent 'don't know'). In many cases P2 was known to be someone else's spouse, a multipartner single (engaged in serial or parallel relationships) or someone (such as a sex worker) well-known for multiple sexual encounters. However, aside from such purely objective interpretations, these figures seem to indicate that a person tends to segment his/her sexual world into the 'first circle' of the stable partner, where fidelity is the key norm and the partner is thus presumed not to have affairs outside the couple, even if the individual

11 'Yes' means that the partner knows the partner has/had another partner. 'I don't know' combines the 'I don't know' and 'no answer' categories in the French and Dutch surveys and 'you have no idea' and 'no answer' categories in the Belgian survey.

in Bajos N., Hubert M., Sandfort T. (eds). Sexual behaviour and HIV/AIDS in Europe. London, UCL Press, 
him/herself is not; and a 'second circle' of occasional, unofficial relationships where the partners are not presumed to limit themselves to an exclusive relationship. The result is an interweaving of objective and subjective reasoning characterized by the construction of a segmented universe in each person's mind whereby the individual manages a complex web of relations and organizes his/her ways of coping with the risk of HIV / AIDS (for example, not using a condom in the supposedly safe inner circle and using a condom, at least when one manages to, in the reputedly dangerous second circle), as Peto et al. (1992) have shown.

To sum up, these data show not only that people with multiple partners are more inclined than monopartners to consider their partners to have several partners as well, but that the various partners are also qualified and/ or perceived differently according to whether they belong to the respondent's first or second circle of relations.

\subsubsection{Tolerating Love Affairs Outside Stable Relationships}

Personal networks are complex worlds, and they allow various - sometime contradictory forms of social conduct because the contexts of relations are segmented and their content differentiated. Each segment (family, friends, colleagues) exerts normative pressure over the partners. In studying this system of normative pressure, we shall make a distinction between ideal and practical norms. We shall assume that ideal norms - what people answer when questioned explicitly on 'what is good?' - consist basically of a general reference within a group, social circle, subgroup or context. Practical norms correspond in this study to how people perceive the actual behaviour of significant others. The effectiveness of these norms is explained by the fact that an individual seeks nothing more than the esteem of his/her significant others and fears nothing more than their disapproval. But, as personal networks are complex, so are normative pressures. They have neither the same direction nor the same weight for different relational contexts. In other words, the direction and force of normative pressures can vary depending on whether the individual is dealing with his/her family, friends, workmates, or fellow students. Then the question is to know how people perceive and manage the normative diversity of their various contexts of sociability, as well as the gap between ideal and practical norms, so as to build a sustainable compromise between expected rewards and punishments.

Of course, it is impossible to analyze all the types of norms involved in sexual life. Amongst the few normative dimensions that surveys enable one to compare, we have selected the topic of concomitant love affairs because this was the only aspect for which connections between 
the network's norms and the respondent's norms and behaviour could be envisaged in more than one survey. We have also selected a subsample of people who have had at least one steady sexual partner for at least five years, guided by the assumption that the issue of concomitant sex affairs may be more crucial for them, since their lives as couples can be centred upon the norm of fidelity in which having another sexual partner takes on more significance than for people who have simultaneous or rapidly changing sequential multiple partners. We shall gauge the social network's normative influence in three steps. First, we shall identify how respondents perceive their various social circles or contexts' norms of sexual relations. Second, we shall identify the respondents' own norms in this regard. Third, we shall study the links between the network's and respondent's norms.

Country-to-country comparisons with regard to this aim are likewise fraught with difficulty but highly worthwhile. If we consider the circles or contexts' norms, the French survey focused on ideal norms, while the Belgian one focused on practical norms and the Dutch survey did not consider the matter at all. In contrast, all three surveys tackled the issue of the respondent's norms, which we shall call 'Ego's norms' hereafter. As a result, the connections between the significant others' norms and those of Ego could be studied using the Belgian and French data only.

\section{Perceived Norms}

As mentioned above, the French survey examined the perception of ideal norms whereas the Belgian survey looked at the perception of actual norms. Separate tables were thus compiled to summarize perceived acceptance of infidelity in respondents' networks according to the French (Table 11.6) and Belgian (Table 11.7) surveys ${ }^{12}$.

The higher percentages recorded in the French survey are doubtless linked to the item chosen ('some agree and others don't'), which provided much more flexibility than the Belgian item.

\footnotetext{
12 The question in the French survey was worded as follows: "'What do you believe your mates and close friends think about having love affairs or sexual relations outside a stable relationship? They are all in favour, some are in favour, others are not / they are all opposed' with the same question being asked with regard to colleagues and family members. The answers 'they all agree' and 'some of them agree, others don't' are grouped together in this table. The questions concerning this matter were included by A. Degenne, who has developed a theory of social circles (Degenne and Forse, 1994). The question in the Belgian survey was worded as follows: "'What model of relationship dominates each of the various circles that 1 am going to list, that is to say, how do people actually behave? In your immediate family, is it the model of..? faithfulness for life / faithfulness as long as one is with somebody; faithfulness with some rare departures; frequent brief affairs or concomitant relationships' with the same question being asked with regard to friends and colleagues. The answers 'faithfulness with some rare departures' and 'frequent brief affairs or concomitant relationships' are grouped together in Table 11.7.
}

in Bajos N., Hubert M., Sandfort T. (eds). Sexual behaviour and HIV/AIDS in Europe. London, UCL Press, 
This forces us to comment on the comparative trends more than absolute levels of the phenomenon in the two countries.

Table 11.6 Perceived acceptance of infidelity in various networks (French survey)

\begin{tabular}{|c|c|c|c|c|}
\hline & Friends & Colleagues & Family & Total \\
\hline & $\%$ & $\%$ & $\%$ & $\mathrm{~N}$ \\
\hline All & 66.8 & 55.2 & 29.4 & 762 \\
\hline \multicolumn{5}{|l|}{ Gender } \\
\hline Men & 70.1 & 63.6 & 32.4 & 426 \\
\hline Women & 63.2 & 46.1 & 26.3 & 336 \\
\hline \multicolumn{5}{|l|}{ Age } \\
\hline $20-24$ & 66.6 & 60.5 & 33.3 & 38 \\
\hline $25-29$ & 72.6 & 63.9 & 29.9 & 141 \\
\hline $30-39$ & 68.6 & 54.8 & 25.3 & 333 \\
\hline $40-49$ & 63.0 & 52.8 & 32.9 & 249 \\
\hline \multicolumn{5}{|c|}{ Place of residence } \\
\hline Rural & 63.3 & 54.5 & 27.1 & 205 \\
\hline Small towns & 65.2 & 53.6 & 26.4 & 194 \\
\hline Towns & 69.7 & 53.6 & 32.1 & 228 \\
\hline Cities: Paris & 71.5 & 62.4 & 34.7 & 135 \\
\hline \multicolumn{5}{|c|}{ Number of partners over last year } \\
\hline 1 & 65.7 & 54.3 & 29.0 & 579 \\
\hline$>1$ & 83.8 & 70.2 & 37.3 & 183 \\
\hline
\end{tabular}


Table 11.7 Perceived acceptance of infidelity in various networks (Belgian survey)

\begin{tabular}{|c|c|c|c|c|}
\hline & Friends & Colleagues & Family & Total \\
\hline & $\%$ & $\%$ & $\%$ & $\mathrm{~N}$ \\
\hline All & 15.2 & 23.7 & 7.4 & 845 \\
\hline \multicolumn{5}{|l|}{ Gender } \\
\hline Men & 17.7 & 31.5 & 7.7 & 372 \\
\hline Women & 13.1 & 17.4 & 7.1 & 473 \\
\hline \multicolumn{5}{|l|}{ Age } \\
\hline $20-24$ & 20.4 & 8.8 & 5.9 & 25 \\
\hline $25-29$ & 8.5 & 22.6 & 4.9 & 128 \\
\hline 30-39 & 16.3 & 23.7 & 6.9 & 364 \\
\hline $40-49$ & 16.1 & 24.9 & 8.9 & 328 \\
\hline \multicolumn{5}{|c|}{ Place of residence } \\
\hline Rural & 4.8 & 19.4 & 4.8 & 20 \\
\hline Small towns & 15.1 & 20.3 & 7.8 & 488 \\
\hline Towns & 12.0 & 33.6 & 3.5 & 102 \\
\hline Cities: Brussels & 22.4 & 34.4 & 10.4 & 235 \\
\hline \multicolumn{5}{|c|}{ Number of partners over last year } \\
\hline 1 & 13.5 & 22.7 & 6.5 & 796 \\
\hline$>1$ & 52.1 & 22.1 & 26.3 & 49 \\
\hline
\end{tabular}

Both tables show that the three circles examined here are not perceived as tolerant by equal proportions of the respondents. The family is perceived as being tolerant of extra-couple sex by the smallest number of people. This perception of family norms is probably grounded in the importance of the roles safeguarded by the family and the influence of gender. First of all, the family is the objective and symbolic stage par excellence for producing the sexual fidelity norm through the role of faithful spouse. Second, admitting concomitant sex affairs in the family circle implies admitting one's own parents' departure from the norm, and that opens a field of uncertainty concerning one's own patrilineal origin and identity. However, as the tables show, the roles of parent and spouse do not prevent the same people being perceived as more tolerant when filling the roles of friends, for example, in other social areas. This means that the perceived norms are less attached to the social images of individuals than to the different roles they play in different circles. This is a very well-known, classical sociological finding. But it is important for prevention: people perceive norms as applying to 'role takers' (Rose, 1962), to one facet of a person (with regard to specific roles and social contexts), not to a total, indivisible 'individual'.

in Bajos N., Hubert M., Sandfort T. (eds). Sexual behaviour and HIV/AIDS in Europe. London, UCL Press, 
While the average respondent perceives these circles differently, differences between respondents also exist. As Tables 11.6 and 11.7 likewise show, a greater percentage of men than women perceive their environments as being tolerant. This doubtless reflects a mixture of objective reality and mental constructs. On the one hand, male extra-relational affairs seem to be accepted more than female extra-relational affairs. On the other hand, the various perceptions of normative orientations can also partly be due to real differences in the kinds of people who belong to the circles and contexts. Indeed, male and female respondents' answers are closest when assessing family norms, but take fairly different stands when they evaluate the norms put across in the working world. The world of friends has an intermediate position. While women's families are also men's families, the same does not apply to friends and colleagues. Several studies (Fischer, 1982) have shown that workmates and friends are more often of the same gender, so that men and women are not evaluating the same workmates' and friends' norms.

There was no gender-based difference in the answers to such questions in the Belgian survey, which evaluated actual norms. In other words, men and women saw the same things. But in the French survey, in contrast, where ideal norms were being evaluated, the gender difference was admittedly smaller in the case of family norms than those of friends and colleagues, but was not negligible. So it seems that the more people are concerned by actual norms, the more dependent they are on the properties of the significant others who compose their social circles. The age-related differences are rather small as a rule. So are the differences associated with residential community size, even though people who live in large cities apparently tend to perceive close contacts as being slightly more tolerant of having several sexual partners (F) or as having slightly more brief affairs or concomitant relationships (B) than those who live in small towns. However, the differences related to locality size were far from impressive and lead us to believe that the difference between large cities and small towns, even villages, are narrowing because of new lifestyles and means of communication. In addition, we must also point out that friends and colleagues and, to a lesser extent, family members commonly include both city-dwellers and people from the country.

Once again, 'multipartnership' appears to be the most decisive factor. In both the French and Belgian surveys, respondents with multiple partners systematically had the highest perception of tolerance to extra-relational sex affairs in the above-mentioned circles. As these respondents themselves have steady partners (for more than five years, by the selection of a subsample) and simultaneously one or several others, their own behaviour often is labelled in Bajos N., Hubert M., Sandfort T. (eds). Sexual behaviour and HIV/AIDS in Europe. London, UCL Press, 
'infidelity' by society. Perhaps these respondents legitimate their behaviour by showing that they are not straying from the norms of the social circles to which they belong. Perhaps also they do meet more tolerant people in the contexts they frequent. But most important is the fact that the proportions of respondents who perceive friends as tolerant are in both surveys and for the two subpopulations (mono- and multipartnership) roughly twice the proportions who judge the family tolerant. Consequently, we can say that the normative differences between these two circles remain constant, whether we look at mono- or multipartner respondents. It then becomes impossible to think of norms as being specific to subpopulations of individuals only through the subcultures they have internalized. In the same subpopulation, they are specific to social roles and narrow social circles. Most often an individual faces various possibly contradictory - normative pressures, depending on the circle in which he interacts at the time and the role relationship in which he is engaged. Finally, Ego's norms have to be understood as a kind of more or less stable compromise among these various pressures.

\section{Ego's Norms}

The wordings of the questions concerning Ego's norms with regard to love affairs vary greatly from one survey to the next, but overall tendencies can nevertheless be picked out. Table 11.8, which summarizes the rates of acceptance of concomitant sex affairs in the three survey populations by gender, age, locality, and number of stated sexual partners over the previous 12 months, shows that the model of fidelity dominates everywhere ${ }^{13}$. Stating that one of the members of a couple's departures is acceptable or approved remains rare. The degree of acceptance of extra-relational sex was clearly lower in the Dutch survey, doubtless because of the more 'black-and-white' wordings of the propositions on which the Dutch respondents were asked to make a pronouncement. This may also explain the relatively high 'no answer' rate (8.5 per cent) in the Dutch survey.

\footnotetext{
13 The questions were worded as follows: 'Each of us has his or her own point of view about love and sexual desire. Do you, personally, agree fully, rather agree, rather disagree or disagree totally with the following ideas? - being faithful to each other is vital for the couple's happiness' (items grouped in this table: 'rather disagree' and 'disagree totally') in the French survey; '"What is your model for a conjugal relationship? Is it the model of ... ? faithfulness for life; faithfulness as long as one is with somebody; faithfulness with some rare departures; frequent brief affairs or concomitant relationships' (items grouped 'in this table: 'faithfulness with some rare departures' and 'frequent brief affairs or concomitant relationships') in the Belgian survey; 'In a steady relationship you should allow each other to be free to have sexual contact with a third person. Do you / completely agree ; basically agree; neutral (50/50) / basically disagree; completely disagree?' (items grouped in this table: 'completely agree' and 'basically agree') in the Dutch survey.
} 
Table 11.8 Ego’s acceptance of infidelity

\begin{tabular}{|c|c|c|c|c|c|c|}
\hline & \multicolumn{2}{|c|}{ Belgium 1993} & \multicolumn{2}{|c|}{ France 1992} & \multicolumn{2}{|c|}{ Netherlands 1989} \\
\hline & $\%$ & $\mathrm{~N}$ &.$\%$ & $\mathrm{~N}$ & $\%$ & $\mathrm{~N}$ \\
\hline All & 8.6 & 845 & 11.6 & 762 & 3.6 & 532 \\
\hline \multicolumn{7}{|l|}{ Gender } \\
\hline Men & 12.2 & 372 & 11.1 & 426 & 5.3 & 190 \\
\hline Women & 5.7 & 473 & 12.1 & 336 & 2.6 & 342 \\
\hline \multicolumn{7}{|l|}{ Age } \\
\hline $20-24$ & 2.9 & 25 & 6.1 & 39 & 0.0 & 23 \\
\hline $25-29$ & 5.8 & 128 & 11.3 & 141 & 5.5 & 73 \\
\hline $30-39$ & 8.7 & 364 & 11.2 & 333 & 4.1 & 242 \\
\hline $40-49$ & 10.0 & 328 & 12.5 & 249 & 2.6 & 194 \\
\hline \multicolumn{7}{|c|}{ Place of residence } \\
\hline Rural & 9.7 & 20 & 8.3 & 205 & 0.0 & 27 \\
\hline Small towns & 804 & 488 & 11.8 & 194 & 2.6 & 389 \\
\hline Towns & 6.2 & 102 & 12.4 & 228 & 7.8 & 116 \\
\hline $\begin{array}{l}\text { Cities: Brussels } \\
\text { /Paris }\end{array}$ & 13.0 & 235 & 16.5 & 135 & & \\
\hline \multicolumn{7}{|c|}{ Number of partners over last year } \\
\hline 1 & 6.5 & 796 & 9.6 & 579 & 3.1 & 513 \\
\hline$>1$ & 55.1 & 49 & 44.5 & 183 & 15.8 & 19 \\
\hline
\end{tabular}

In the Belgian survey women were clearly less willing to accept departures than men. The pattern was similar in the Dutch survey, but not statistically significant. There was no genderbased difference in the French responses. The age effect was relatively weak in this area. Table 11.8 shows the very clear effect of the degree of urbanization in the three countries. This is in keeping with classic studies of the metropolis (Grafmeyer and Joseph, 1979) and studies of urban subcultures (Fischer, 1982), according to which extra relational sex and marginal practices and values find specialized networks and niches in the segmented diversity of urban settings, where they become locally the rule and are protected from dominant outside pressures. Still, here yet again, having multiple partners led the pack by several lengths as the most decisive explanatory variable in all three surveys (with a slight reservation for the Dutch survey, given the very small sample size). Inversely, a small group of single-partner respondents accepted extra-relational sex affairs. Thus, between an overwhelming majority of single-partner respondents having adopted monogamy as their model and a small group of in Bajos N., Hubert M., Sandfort T. (eds). Sexual behaviour and HIV/AIDS in Europe. London, UCL Press, 
multipartner respondents condoning departures we find a small group of people who exhibited a gap between norms and behaviour at the time they were surveyed.

In the three surveys, respondents with multiple partners (and who, we must recall, were all involved in stable relationships lasting more than five years) were five to eight times more tolerant of extra-relational sex than one partner respondents. Actually, for the former, there is a relative convergence between practices and norms, but a very interesting phenomenon is reflected by figures not shown in the table, namely, that about half of the respondents with multiple partners disapproved of extra-relational sex affairs. Are these people 'cheating' on their steady partners because they have 'succumbed to temptation'? Are their steady relationships punctuated by regular crises (we know that marital life is not calm) that prompt them occasionally to 'look elsewhere, albeit regretfully'? Or are they people whose lasting relationships are nevertheless unstable, consisting of a series of periods of monogamy alternating with temporary separations?

\subsubsection{Correspondence between the Network of Significant Others' Norms and Those of Ego}

The degree to which Ego's and significant others' norms correspond can be verified for the Belgian and French surveys only ${ }^{14}$. Overall, the data reflect a clear social network effect. Yet the individual is not a carbon copy of his or her networks, as most of the respondents who perceived their circles as being more favourably disposed to or practising extra-relational sex did not condone departures themselves.

Table 11.9 summarizes the percentages of respondents who accepted sexual contact with a third person outside a relationship (at least in part) versus their perceptions of the practical norms (Be1gian survey) or ideal norms (French survey) assumed to prevail among their relatives, friends, and colleagues. However, the most salient revelations in this table are the large differences between the Belgian and French survey responses. This seems to confirm the hypothesis that the social network norms that influence individuals most strongly are practical norms (taken into account in the Belgian survey) rather than ideal norms (taken into account in the French survey).

The concordance between network norms and Ego's norms is maximal for the family network. Now, this is also the type of circle with regard to which individuals who dare to perceive it as

\footnotetext{
14 The questions summarized in this table are the same as for Tables 11.6 and 11.7. in Bajos N., Hubert M., Sandfort T. (eds). Sexual behaviour and HIV/AIDS in Europe. London, UCL Press,
} 
being favourable to extra-relational sex are in the minority (29.4 and 7.4 per cent in the French and Belgian surveys, respectively, versus 66.8 and 15.2 per cent, respectively, with regard to the circle of friends and 55.2 and 23.7 per cent, respect1vely, with regard to colleagues). This may be the place to take up a hypothesis put forward elsewhere (Ferrand and Mounier, 1998), to wit, that the more a behaviour or norm is practised only by a social minority, the greater the effect of the network of significant others supposed to uphold it. Families that are perceived as tolerant are normative niches whose power is enhanced by their being a minority in an environment that massively conveys the fidelity norm.

Table 11.9 Proportions of Ego's acceptance of infidelity by perceived practical norms (Belgium) and ideal norms (France)

\begin{tabular}{|l|r|r|r|r|}
\hline & \multicolumn{2}{|c|}{ Belgium 1993} & \multicolumn{2}{|c|}{ France 1992} \\
\hline & \multicolumn{1}{|c|}{$\%$} & \multicolumn{1}{c|}{$\mathrm{N}$} & \multicolumn{1}{c|}{$\%$} & $\mathrm{~N}$ \\
\hline AIl & 8.6 & 845 & 11.6 & 762 \\
\hline Family: do accept infidelity & 47.7 & 69 & 18.6 & 231 \\
\hline Family: do not accept infidelity & 5.3 & 768 & 8.6 & 531 \\
\hline Friends: do accept infidelity & 29.4 & 144 & 14.0 & 545 \\
\hline Friends: do not accept infidelity & 4.3 & 592 & 6.6 & 217 \\
\hline Colleagues: do accept infidelity & 18.0 & 215 & 13.3 & 452 \\
\hline Colleagues: do not accept infidelity & 4.4 & 453 & 9.4 & 310 \\
\hline
\end{tabular}

Still, the weight of Ego's opinions and behaviour may still be decisive in the family itself, since Ego is a key member of the family. Ego thus gives the pitch, especially if he/she is an adult. In considering the family, one probably has to allow for Ego's influence even more than for other networks. What is more, the closer the link of the normative content under consideration with the circle's very functioning, the more the circle will be perceived to be in agreement with the member's own norms.

\subsubsection{Conclusions}

These few comparisons suffice to show the importance of taking network effects into account when examining HIV / AIDS risk-related attitudes and behaviour. Individuals do not face such risks as individuals, but as members of social circles who are engaged in various interpersonal relations. Most individuals also have one or more confidants with whom they in Bajos N., Hubert M., Sandfort T. (eds). Sexual behaviour and HIV/AIDS in Europe. London, UCL Press, 
can talk about sexuality. Interpersonal knowledge and control are affected by what happens within these networks of confidants. The comparison also shows that behaviour varies depending on whether or not one knows people with HIV / AIDS. Finally, the various circles of relatives, colleagues and friends exert different normative influences and exercise different social controls over individual attitudes and behaviour.

The effects of sociability must be taken more into account when designing prevention campaigns. In this connection, the comparisons that have been presented above suggest the following four main avenues of research that may be of interest for prevention.

First, the influence of each factor, such as having confidants or knowing PWHA, on the phenomena studied here was considered separately for reasons of facility. We may hypothesize, however, that these factors are actually interrelated. Multivariate analysis would doubtless reveal a certain number of specific sociability types defined by a set of traits bound by 'elective affinity', as Max Weber would say (for example, a single-gender specific age group in an urban environment with a specific population density and linked by a particular socio-occupational culture in which ideal norms are partially contradicted by practical norms, partner's partners tend to ignore each other, and confidants are rather rare). Each of these types corresponds to normative frameworks, relational experiences, and social controls that react differently to prevention messages and thus expose their subjects to variable degrees of risk. Analyses such as the one presented here should be followed by attempts to identify these different types of sociability with a view to using them, if necessary, to design suitable preventive action.

Second, the comparisons have also shown that each individual is linked to several different networks. The norms that prevail in Ego's family may be contradicted by his colleagues, forcing him to play different roles in different settings. As a result, the concordance between an individual's norms and those of his/her social networks can never be total. Network theory calls attention to the fact that the search for the significant other's esteem is the most widespread motivation behind this process of individual adaptation. However, when Ego has different significant others who expect different, even contradictory, types of behaviour from him, he may be obliged to segment his social universe in practice and/or in his mind (Peto et al., 1992). Analyzing social networks consequently also means examining the ways these various influences fit (or do not fit) together and individuals manage (or fail) to arbitrate among the diverse normative pressures with which they must cope. Indeed, this issue of how 
individuals cope with the tension between their networks merits further investigation, for vulnerability to risk is often linked to difficulties in this area.

Third, network analysis begins as soon as the researcher no longer limits the scope of his/her investigation to the relationship between two partners, but broadens it to include the 'absent third parties', in a word, with the shift from the dyad to the triad. These 'absent third parties' may be the other's other sexual partners. To have a satisfactory, lasting relationship with a steady partner, Ego may have a tendency to ignore the possibility that the steady partner may him/herself have other partners. Similarly, in the budding phase of a new relationship, Ego may not want to worry about the other's sexual partners and the risks they may represent. This matter of knowing one's partners' partners is a major problem for prevention that should be taken into account in surveys and the ways the data are analyzed.

Fourth, in several studies, Ferrand and Mounier (1990, 1993b, 1998) have shown the importance of confidants' networks in determining individuals' representations and behaviour. Indeed, it seems reasonable to posit that in many cases the transformation of representations and behaviour is more a collective than an individual process that occurs in interactions between confidants, and is subject to the reciprocal reinforcing effects that are characteristic of very close groups. Prevention should be able to rely on more extensive knowledge of what goes on in these networks of confidants' and produce messages that these processes can assimilate. 


\section{References}

CATANIA, J.A, KEGELES, S.M. and COATES, T.J. (1990) 'Towards an understanding of risk behavior: an AIDS risk reduction model (ARRM)', Health Education Quarterly, 17, pp. 53-72.

COHEN, M. and HUBERT, M. (1997) 'The place of time in understanding sexual behaviour and designing HIV / AIDS prevention programs', in VAN CAMPENHOUDT, L. et al. (Eds) Sexual Interaction and HIV Risks. New Conceptual Perspectives in European Research, London: Taylor \& Francis.

DEGENNE, A (1983) 'Sur les réseaux de sociabilité', Revue Française de Sociologie, 24, 1, pp. 109-18.

DEGENNE, A. and FORSE, M. (1994) Les réseaux sociaux, Paris; Armand Colin. FERRAND, A. and MOUNIER, L. (1990) Relations sexuelles et relations de confidence Analyse de réseaux, Enquête méthodologique financée par I'ANRS, LASMAS-CNRS, Paris.

FERRAND, A and MOUNIER, L. (1993a) 'Paroles sociales et influences normatives', in SPIRA, A, BAJOS, N. and LE GROUPE ACSF, Les comportements sexuels en France, Paris: La Documentation Française.

FERRAND, A and MOUNIER, L. (1993b) 'L'échange de paroles sur la sexualité : une analyse des relations de confidence', Population, 5, pp. 1451-76.

FERRAND, A and MOUNIER, L. (1998) 'L'influence des réseaux de confidence sur les relations sexuelles' in BAJOS, N. et al. (Eds), La sexualité aux temps du sida, Paris, PUF.

FERRAND, A. and SNIJDERS, T. (1997) 'Social networks and normative tensions', in VAN CAMPENHOUDT, L. et al. (Eds) Sexual Interaction and HIV Risks. New Conceptual Perspectives in European Research, London: Taylor \& Francis.

FISCHER, C.S. (1982) To Dwell Among Friends: Personal Network in Town and City, Chicago: University Press.

GRAFMEYER, Y. and JOSEPH, 1. (1979) L'Ecole de Chicago (Recueil de textes), Paris: Champ Urbain.

KRETZSCHMAR, M., REINKING, D.P., BROUWERS, H., VAN ZESSEN, G. and JAGER, ].C. (1994) 'Network models; from paradigm to mathematical tool', in KAPLAN and BRANDEAU (Eds) Modeling the AIDS Epidemic: Planning, Policy and Prediction, New York: Raven Press. 
MARSDEN, P.V. (1990) 'Network data and measurement', Annual Review of Sociology, 16, pp. 435-63.

PETO, D., REMY,J., VAN CAMPENHOUDT, L. and HUBERT, M. (1992) Sida: l'amour face la peur, Paris: L'Harmattan.

POLLAK, M. (1988) Les homosexuels et le Sida. Sociologie d'une épidémie, Paris: Métailié. ROSE, AM. (Ed.) (1962) Human Behavior and Social Processes: an Interactionist Approach, London: Houghton Mifflin.

WASSERMAN, S. and FAUST, K (1994) Social Network Analysis, Cambridge: Cambridge University Press.

WELLMAN, B. and BERKOWITZ, S.D. (Eds) (1988) Social Structures. A Network Approach, Cambridge: Cambridge University Press. 